\title{
Arancini, identity, and the refugee debate in Sicily
}

Enzo Zaccardelli ${ }^{1}$ and Jeffrey H. Cohen ${ }^{2}$

\begin{abstract}
In August of 2018, the Italian national government probibited North African passengers onboard the Diciotti from disembarking in Catania, Sicily. The ship had docked amid an ongoing debate over how Italy should respond to an increasing number of immigrants and refugees arriving to the nation's shores. Pro-migrant Sicilians came to the dock wielding arancini--fried rice balls--which are emblematic of the island's history and culture, as a way to symbolically welcome the migrants onboard the Diciotti. Nationalist Sicilians came as well to counter-protest the pro-migrant group. This paper asks first, who are the opposing groups (pro-migrant and nationalist Sicilians) and why did they adopt arancini? Second, how does arancini become a symbol of welcome and at the same time inhospitality? Third, how does the encounter become a stage for the larger debate over the meaning of identity in Sicily? By shifting the focus towards the host population and how it contests the meanings of such important local symbols, we capture the complexities of reception and debates over how natives perceive and receive migrants.
\end{abstract}

Keywords: Italy; food; identity; refugees; reception; Sicily; migrant

\section{Introduction}

In August of 2018, the Italian national government prohibited North African passengers onboard the Diciotti from disembarking in Catania, Sicily (Ruta, 2018). The ship had docked amid an ongoing debate over how Italy should respond to an increasing number of immigrants and refugees arriving to the nation's shores. While the ship sat in Catania, groups of promigrant and nationalist Sicilians confronted each other. Supporters and opponents arrived on the dock wielding arancini (rice balls), a traditional food of Sicily and a symbol of Sicilian hospitality.

My paper asks first, who are the opposing groups (pro-migrant and nationalist Sicilians) and why did they adopt arancini? Second, how does arancini become a symbol of welcome and at the same time inhospitality? Third, how does the encounter become a stage for the larger debate over the meaning of identity in Sicily, and how does identity play a role in the conflict between migrant reception and rejection around the world?

Understanding the role of arancini in the protests - both for and against the immigrants - is an opportunity to explore food's role in the negotiation of cultural identity. Moreover, by shifting our gaze from the immigrants to arancini and its adoption by pro-migrant and nationalist forces, we capture the complexities of reception and debates over how natives perceive and receive migrants. What appears to be a refugee crisis is actually a crisis of nation states to adapt to mass migration, as well as an identity crisis for citizens, which appears to be

\footnotetext{
${ }^{1}$ Enzo Zaccardelli, The Ohio State University, United States. E-mail: zaccardelli.5@buckeyemail.osu.edu.

${ }^{2}$ Jeffrey H. Cohen, The Ohio State University, United States. E-mail: cohen.319@osu.edu.
} 
occurring across the globe (Algiers, 2021). Thus, we move the discussion away from the "refugee crisis" to the dynamic construction of identity, as local groups debate the meaning and value of their welcome.

\section{Background}

Sicily's history is a story of connections that link the Mediterranean basin. The island's heritage is shaped by the many groups who arrived on its shores, including the Greeks, Carthaginians, Normans and Vandals, Byzantines, Arabs, Berbers, French, Spaniards, Italians, and also Americans briefly in the 20th century (Wright, 2003). One consequence of these connections was the introduction of many new foods, including arancini. Arancini, introduced during Arab control of the island (831-1061 AD), are fried rice balls stuffed with a variety of ingredients (Wright, 2003). Arab chefs in Sicily likely created Arancini from a combination of the ingredients they carried, as well as other ingredients readily available (Wright, 2003:380). Now it is emblematic of contemporary Sicilian identity.

Once a nation of emigrants, immigration is now one of the most polarizing, divisive issues in Italy, and the two groups of Sicilians had formed before the Diciotti's arrival (Urso, 2018; Ratti, 1931). Pro-migrant protesters brought arancini to welcome refugees. It served as a symbol of their morality. While it might appear that they welcomed the Diciotti, their motivation was not focused on the ship or its passengers. The supporters believed it was their obligation to accept those in need, wherever they may come from and regardless of the economic benefits (or costs) they may hold. This morality is rooted in Catholicism, which teaches its followers to give to others and help those in need, including through the offering of food (Marrujo, 2010) and to transcend localities; everyone is a creation of the same God. The pro-migrant group applied ideals of Sicilian hospitality and Catholicism, parallel to statements from the EU (Conti, Di Mauro, and Memoli, 2019). For the pro-migrant camp, the offering of arancini to hungry migrants, regardless of their origin, was fundamental to a Sicilian morality with biblical roots (Ben-Yehoyada, 2015). In other words, those in the global moralist camp promoted a moral commitment to accept refugees and migrants that was part of being Sicilian.

For the moralists, the drama surrounding the Diciotti and its passengers was not about what to do with the migrants; rather, it was concerned with how best to represent Sicily to Italy and the world and to other moralists. Combining their moral obligations and embracing of shared EU goals as well as their shared stance on migrant reception, I will refer to this pro-migrant group as global moralists.

The global moralists use arancini to welcome the stranger. The nationalists, on the other hand, supported the government's rejection of the Diciotti; it was not simply a rejection of the passengers and the dangers that migrants and refugees might pose, rather, it was a signal to Italy that they were committed to a strong nationalist agenda.

The two groups are reading the same histories yet interpret arancini and Sicilian culture differently. The global moralists promote interconnectedness and celebrate the heterogeneous roots of Sicilian history, contributing to their sense of obligation to help the outsiders arriving via the Mediterranean (Ben-Yehoyada, 2015, 2017; Giglioli, 2017; Yitmen and Verkuyten, 2017). Contrarily, the nationalists point towards a historical conquest from the same region as proof of their danger, rejecting their arrival (Schack and Witcher, 2020). Global moralists 
and nationalists debate the value of immigration, but the agricultural and culinary contributions from the Arabs and Berbers to Sicilian foods and cooking cannot be denied: much of these foodstuffs were introduced in the 10th century from North Africans (Ruggeri, 2018:402).

\section{Sicilian schism in the debate on migration and the diciotti}

The migration debate in Italy intensified in the years leading up to the arrival of the Diciotti. The number of migrants arriving throughout Italy, particularly by sea reached new heights over the last decade. From 2014 to 2017, Italy reported 622,531 migrant sea arrivals (Varrella, 2020). The following year, the anti-migrant party became the strongest party in a coalition government that gained control of the State (Abbondanza and Bailo, 2018). Growing nationalism, Islamophobia, and anti-immigrant rhetoric influenced movers and were important factors in a drop in the number of sea arrivals to 23,037 in 2018 (Varrella, 2020). The number of arrivals declined again in 2019 to 11,471 (Varrella, 2020).

Most migrant ships came from North Africa. Libya tends to be the main departing country for sea arrivals to Italy, with Tunisians usually the most common nationality arriving to Italy by sea (Varrella, 2020). In 2018, 7 out of the 10 most common ports for migration were in Sicily--the remainder were in Calabria and Sardinia (Varrella, 2020). Catania was the third most common destination and gained political attention like the island of Lampedusa, famous for its large population of newly arrived migrants (Zerback et al., 2020; Frazzetta and Piazza, 2020). ${ }^{1}$

Migration was one of the most polarizing topics leading up to Italy's 2018 general election (Abbondanza and Bailo, 2018). Nationalists became increasingly strong, as they emphasized anti-migration policies, a purist identity, and an anti-EU platform (Abbondanza and Bailo, 2018). During the 2018 general election, the anti-migration, anti-establishment (Northern) League, or Lega (Nord) spread throughout the country, transforming from a regional to a national party, and, soon after, becoming the de facto leader within a peculiar coalition government (D’Alimonte, 2019).2

Political unrest, religious persecution, and economic precarity drive migrants and refugees to Italy (Camarena et al., 2020). Given its geographic location and historical attachment, it makes sense that many people leaving North Africa look towards the Italian shores as a gateway to the EU and Germany--a preferred destination (Frazzeta and Piazza, 2020).

\section{Contesting symbol of arancini: two sides}

Arancini has been a part of the clash between the two groups over Sicilian identity. One group sees arancini as connected to the island's history, its heterogeneity, and its values of hospitality-being a good Sicilian and a good Catholic. This group, the global moralists, extended arancini as a symbol of inclusion for outsiders. They view Sicilian history as full of interactions and connections within a very large geographical and cultural range, especially from the southern Mediterranean (Giglioli, 2017; Albahari, 2009; Ben-Yehoyada, 2015, 2017; Yitmen and Verkuyten, 2017). In other words, they are obligated to help and offer hospitality to those in need and with whom they have interacted throughout history. Nationalists, on the other hand, view arancini as a local symbol of what it is to be truly Sicilian, just as they do other foods thought to be quintessentially Sicilian (Montanari, 2012). For the nationalists, Sicily is home--it may welcome visitors, but it does not include outsiders as natives and limits 
the recognition of the migrant as anything more than a dangerous stranger. Some nationalists may even use the same history referred to by the global moralists as alleged proof that outsiders are dangerous conquerors. Hence, nationalists supported the government's original decision to prohibit the migrants from disembarking, while the global moralists opposed and protested it (Cholewinski and Taran, 2010).

The protesters who supported the Diciotti migrants in August 2018 extended arancini as a gesture of welcome. In interviews with the Italian newspaper La Repubblica, organizers and participants described arancini as "a symbol of sharing for our city" and "a symbol of inclusivity" as well as one of "welcome and assistance" (Ruta, 2018). One protester stated more generally that "food in Sicily has always been the way you welcome guests" (Ruta, 2018). Some protestors even brought signs depicting arancini that read "\#Catania Welcomes," a hashtag and motto which Sicilians later used on Twitter to continue the debate online (Rannard, 2018). As another protester noted, "[Arancini] is also a symbol of unity between the two sides of the sea," a claim that acknowledged the shared history between Sicily and North Africa (D'Ignoti, 2019).

While food is important in welcoming the guest, there is a clear discrepancy in the symbolic importance of arancini as it is used by the two groups and by whom they believe is worthy of receiving arancini-and by extension, hospitality in general (D'Ignoti, 2019; Derrida, 2000). Derrida's emphasis on the host instead of the guest is useful as we understand these events in Sicily. According to Derrida (2000), a host uses hospitality to maintain his or her status and identity. The migrant (or guest) is a component in forming the host's identity, but not the main focus; rather, one can argue the host's identity is defined by the care shown towards the guest. Following this logic, the host is at the center of the discussion and hospitality is a sign of their status and impacts the very nature of the relationship between the host and the guest or stranger (Algier, 2021; Scherer, 1993).

Arancini are used in divisive ways by global moralists and nationalists. Supporters offered arancini to travelers in need as a part of their Sicilian culture and to promote an identity as hosts. They acknowledged their historical solidarity through a symbolic culinary exchange. Critical to the nationalists is their disregarding of the Arab origins of Sicilian foods. Massimo Montanari writes that Sicilians take great pride in their food, such as eggplant, another Sicilian staple, yet hate to be reminded that it was introduced from North Africa (2012). Even if history is important, arancini has undoubtedly changed a great deal since its introduction in the 10th century. The nationalist Sicilians rejecting the arrival of the Diciotti displace arancini from its Islamic, Arab origins (Reddy and van Dam, 2020). In fact, the cooking and consumption of pork has been used to reinforce nationalist identity against Jews and Muslims in several countries (Bilefsky, 2016; Adum-Atta, 2020). The nationalists reassert their local identity as Catholic Sicilians through local dietary customs that contradict Islamic dietary laws. In other words, they place their own identity in opposition to the migrants, creating divisions and rejecting reception.

The two groups differ in who is worthy of receiving the arancini-and what it represents-and, thus, who can be included in their community, both symbolically and physically (Mach, 1993). For the global moralists who supported the Diciotti's passengers, they are extending their global moralism through a Sicilian symbol, while the nationalists support the government, to reinforce a strong national identity at the local level. 
National or local identity can be used to promote acceptance of outsiders. Ester Driel and Maykel Verkuyten recognized this phenomenon in the town of Riace in southern Italy. Sometimes a local community's strong sense of identity can actually "stimulate the reception of refugees" (2019: 16). Because hospitality plays a big role in such a close-knit local community that prides itself on its cultural heritage, offering hospitality to people in need is a moral obligation that reinforces local identity. Due to this and other factors, locals usually appear in such cases to be more accepting of refugees (Giglioli, 2017; Albahari, 2009). Another example of this took place when a priest gave a sermon onboard a migrant ship in the Mediterranean amid the influx of migrants into Italy; a strong sense of Sicilian identity can stimulate migrant or refugee reception, through a cultural-religious moralism (Ben-Yehoyada, 2015). While giving his sermon, the priest proclaimed, "As Sicilians and Christians...you cannot turn down those who knock on our hearts, even before they knock on our doors: our identity and our culture prohibit such closure" (Ben-Yehoyada, 2015:391). In his words, the priest proclaimed that acceptance of refugees is mandatory from both a religious and cultural perspective-which he tied together - to help those in need. The acceptance of these refugees is what keeps Sicilian culture and Catholic ideals alive. In both the case of the Diciotti and the sermon at sea, migrants and refugees were the ones in need. Contrary to the assumptions of the nationalists then, allowing and celebrating the migrants preserves Sicilian culture and identity.

The example of Sicilian protesters using the local symbol of arancini to promote a global moralism surrounding international migration demonstrates Mintz and Dubois' point that the global does not necessarily have to replace the local (2002). The global cannot replace the local. Through sharing arancini, global moralists embrace traditional ideals of hospitality and reapply them. The nationalists reject that globalist ideal and push arancini as a symbol that emphasizes its local value. The exchange between the two groups created a dialectical process wherein the symbol (arancini) is transformed and used in an ongoing debate that is ultimately focused on the construction of local identity and the place of Sicily in the Italian State (Comaroff and Comaroff, 2008).

The importance of arancini in this process is clear given the almost obligatory traditional hospitality that is critical to Sicily and Sicilian identity. Tierney and Ohnuki-Tierney argue that we must pay attention to the local as well as the global to understand how traditions, meanings, and food create identity and belonging on the global stage and through migration (2012). Although this debate and internal struggle relate directly to the global, it is taking place at a very local level — the two competing camps are protesting at a port in Catania, illustrating this point that we must focus on both the global and local.

\section{Discussion}

By refocusing on host populations, not movers, it is clear that the events that took place in Catania's port were part of a debate around the meaning of local identity and being Siciliannot a refugee crisis or an issue of immigration and settlement. As Michel Agier puts it, what appears to be a refugee crisis is actually a crisis of nation states to adapt to mass migration, as well as an identity crisis for citizens (2021). The use of arancini in the context of migration reception briefly continued on Twitter, with 315,000 tweets about the Diciotti and the events at the docks, organized around the competing ideals of the two groups of Sicilians (Rannard, 2018). Tweets ranged from the global moralists using the hashtag "Catania Welcomes" 
(\#CataniaAccoglie) — referencing a sign held during the protests that depicted arancini-and "National Disgrace," to those in support of Matteo Salvini's (Northern) League (Rannard, 2018). The latter tended to show support and solidarity with Salvini, using phrases like "No Way [can/should we accept more migrants]" (Rannard, 2018). Despite the back and forth debate, there was no clear winner and the symbolism of arancini as it relates to migration was short-lived.

The debate quickly ended as both parties moved on with their daily lives; and yet, much can be learned from this example. Just as ethnography focuses on the bigger picture and lessons, the importance of this case study comes from a focus on the briefest of moments, and what such a moment can teach us in general about identity and how local symbols are contested (Kristiansen et al., 2015).

By focusing on the small moments within the host community this case study adds a new dimension to migration literature. More specifically, it focuses on how two populations in the host community view themselves and outsiders, and how the movers are represented and misrepresented as they are caught between these two host groups in their debates. The Diciotti captures Alessio D'Angelo's argument that 'What has been labeled as a 'refugee crisis' is first and foremost a crisis of international politics and the result of inadequate response mechanisms at the local level" (2018). Building on D'Angelo's work, I argue these events are part of a struggle over identity — not a refugee crisis — at the local level, the product of a clash between nationalism and globalism that plays out against the nature and meaning of migration. In other words, I maintain that the real "fight" taking place is not over migrant arrivals, but rather, between Sicilians of differing worldviews who interpret history in terms of conflicting moralities. The host population is not monolithic (Makarychev, 2018). Though nationalist Sicilians may genuinely dislike or hold prejudices towards migrants, the real conflict is not the Sicilian versus the foreigner (nor the Sicilian supporting the foreigner), but rather Sicilian versus Sicilian and the changing nature of local identity.

Would either group have shown up to the dock if the Diciotti had simply disembarked its passengers? Nationalists, who already supported the decision to keep the migrants onboard, only went to counter-protest the global moralist group; the nationalists and their ideas were in ascendance prior to these protests (Abbondanza and Bailo, 2018). The nationalists would likely not have shown up if global moralists had also avoided the docks. For the global moralists, their presence would not change whether or not those migrants were allowed to disembark (at least not directly), as that was the State's decision. Instead, they demonstrated, through symbolically offering arancini, their hopes for Sicily. This event then is a political and identity issue, not a migration issue.

The Sicilian example is exemplary of the same fight taking place in other nations and states as well, such as France, the US, Germany, and Mexico, among others. There is an ongoing, worldwide debate around ideology - the moral globalist versus the nationalist. While these two groups are found internationally, these are internal fights within their respective nations (Hiers, Soehl, and Wimmer, 2017). Indeed, the refugee may be portrayed as the (foreign) enemy, but for these nationalists, their internal enemy-the Sicilian or Italian global moralist - is actually the bigger threat, as it is ultimately the part of the State that allows or prohibits migrant ships from arriving. The two groups involved in this internal identity crisis oppose each other in every manner. The internal enemy or threat is more frightening, more worrisome, as it jabs at the very essence of that community's identity or way of life, the 
foundation of that community, from within. These same circumstances are taking place globally and Sicily offers an interesting insight into this through the unique role of arancini in this debate and process (Bieber, 2018). The Sicilian example captures how sides form quickly as they debate morality and the status of migrants and national identity.

This paper analyzes how different groups within the same community contest and use a local symbol-arancini- to establish their own identities in relation to each other and against competing ideologies. By refocusing on the host, and on the symbolism of food, we can see how people use food as a political tool, and how food is employed to influence what it means to be Sicilian. Since no food is actually exchanged, it becomes obvious that these acts were to project each group's stance publicly: strong national identity on one hand, and global moralism based on universal human rights on the other hand. Both groups want their stance to be the one that exemplifies Sicily and Sicilian identity.

The global moralists reveal themselves by this symbol to foreigners, while the nationalists keep the local symbol local, by and for Sicilians only. This is another example of the politics of food (Schwarz, 2017). The symbolic demonstration of offering arancini relates to how each group of Sicilians views themselves in the current state of the nation and world (Gattinara, 2017; Pollan, 2009). Indeed, food is a critical tool to "understand individual cultures and societies, especially in the context of global and historical flows and connections," and the offering of arancini in the context of the Diciotti exemplifies that (Tierney and OhnukiTierney, 2012:117; and see Wolf, 1982).

Locals engaged in dialogue with the State through arancini. ${ }^{3}$ The global moralists and nationalists are interested in having their voices heard by the Italian State even as they frame their arguments around the arrival of migrants on the Diciotti. For the global moralist Sicilians, arancini is a symbol of a shared Mediterranean history and globalization, while for the nationalists, arancini is a symbol of the Italian State and Sicily. Both groups arrived on the dock, contesting not only each other in that local space, but also engaging in dialogue with the State (Rannard, 2018; Ruta, 2018). While certain foods (and symbols) can be considered iconic of a given place, this case study illustrates that there is much greater complexity than a simple representation of a place, as the food is employed by groups with differing agendas in varying ways (Albahari, 2007; Wolf, 1982).

Both groups were focused on reinforcing Sicilian identity, albeit in very different ways. Nationalists do so by keeping arancini for themselves and rejecting its international origins as well as the migrants. They believe they were preserving Sicilian culture from outside forces that would destroy the island (Hiers, Soehl, and Wimmer, 2017). As stated, global moralist Sicilians believe that offering arancini, and food in general, reinforced the Sicilian obligation of hospitality, to help those in need and/or to travelers. It can be argued then that the very essence of Sicilian culture is contested through the symbolic offering of food, which, given the historical and cultural context explained above, holds a much deeper meaning than would first appear.

\section{Conclusion}

The act of offering, or not offering, the arancini is not only symbolic, but it is also politicized, with each side taking a stance on whether or not they believe the migrants should be a part of the Sicilian community, and they use arancini as a critical symbol to do so. Arancini is part of 
a dynamic debate, or, as Algiers' argues, an identity crisis, taking place among the host populations around competing ideas of national identity, global moralism, and what it means to be Sicilian (2021). By refusing to offer arancini to the migrants, the nationalists symbolically refuse the migrants' entry into their country, marking a clear distinction between Sicilians and the foreign outsiders, the Other. These events demonstrate the importance of the ethnography of small things-brief moments can teach us a lot about the complex relationships of migrant reception and identity. By looking at this case from the lens of the hosts, we discover how reception becomes more than the arrival of immigrants - it is a space for a debate about identity, human life, and morality.

As demonstrated by this paper, migration studies benefit from incorporating a host-oriented approach. This paper shows how food becomes a contested symbol among the hosts, who are struggling for control over what it means to be Sicilian in the present day throughout their everyday lives. Importantly, we can use this Sicilian case study to examine how identity in other nations plays a role in the inner-conflict between migrant reception and rejection. Incorporating this host-oriented approach into migration studies could prove extremely helpful in an increasingly globalized yet nationalist world.

\section{Footnotes}

1. The island nation of Malta is also a hotspot for migrant arrivals by sea, given its geographic location between Sicily and Tunisia, and has had several migrant rows with Italy in the past few years, and especially since the 2018 general election.

2. Interestingly, this same party is notorious for its anti-southern/anti-Sicilian past, and actually used to oppose Sicilian and southern Italian immigration to the North; it has since changed this stance to focus on greatly reducing international immigration-Othering foreigners, such as Tunisians or Libyans, for example, instead of Sicilians or Calabrians (Giglioli, 2017; Cole, 2005).

3. Locals engage in dialogue through arancini with the State as well as with each other. The global moralist and nationalist groups are both focused on each other and the State, not the migrants, because it is ultimately the national government's decision whether the migrants can disembark or not. While certain foods can be considered iconic of a given place, this case study illustrates that there is much greater complexity than simple representation of a place, as the food is employed by groups with differing agendas in varying ways.

\section{References}

Abbondanza, G. and Bailo, F. (2018). "The Electoral Payoff of Immigration Flows for Anti-Immigration Parties: the Case of Italy's Lega Nord.” European Political Science 17: 378-403.

Adum-Atta, R.A. (2020). "The Politics of Purity, Disgust, and Contamination:Communal Identity of Trotter (Pig) Sellers in Madina Zongo.” Religions 11(421):1-12.

Albahari, M. (2009). "Between Mediterranean Centrality and European Periphery Migration and Heritage in Southern Italy.” International Journal of Euro-Mediterranean Studies 1.2: 141-162.

Albahari, M. (2007). "Religious Symbols, Made in Italy." ISIM Review 19:30-31.

Algiers, M. (2021). The Stranger as my Guest: A Critical Anthropology of Hospitality. Cambridge, UK: Polity Press.

Ben-Yehoyada, N. (2017). The Mediterranean Incarnate: Region Formation between Sicily and Tunisia since World War II. Chicago: University of Chicago Press.

Ben-Yehoyada, N. (2015). "“Follow me, and I will make you fishers of men': The Moral and Political Scales of Migration in the Central Mediterranean." Journal of the Royal Anthropological Institute 22(1): 183-202.

Bieber, F. (2018). "Is Nationalism on the Rise? Assessing Global Trends." Ethnopolitics 17.5: 519-540.

Bilefsky, D. (2016, Jan 26). "Denmark's New Front in Debate Over Immigrants: Children's Lunches.” The New York Times. https://www.nytimes.com/2016/01/21/world/europe/randers-denmark-pork.html.

Camarena, K.R., et al (2020). "Political and Environmental Risks Influence Migration and Human Smuggling across the Mediterranean Sea". PloS one, 15(7). 
Cholewinski, R. and Taran, P. (2009). "Migration, Governance and Human Rights: Contemporary Dilemmas in the Era of Globalization." Refugee Survey Quarterly 28(4):1-33.

Cole, J. (2005). The New Racism in Europe: A Sicilian Ethnography. Cambridge: Cambridge University Press.

Comaroff, J. and Comaroff, J.L. (2008). "Occult Economies and the Violence of Abstraction: Notes from the South African Post-Colony.” Journal of the American Ethnological Society 26(2): 279-303.

Conti, N., Di Mauro, D., and Memoli, V. (2019). "Citizens, Immigration, and the EU as a Shield." European Union Politics 20.3: 492-510.

D’Angelo, A. (2019). "Italy: the 'illegality factory'? Theory and Practice of Refugees' Reception in Sicily." Journal of Ethnic and Migration Studies. 45(12): 2213-2226.

D’Alimonte, R. (2019). “How the Populists Won in Italy." Journal of Democracy 30.1.

Derrida, J. (2000). Of Hospitality. Stanford: Stanford University Press.

D'Ignoti, S. (2019, Apr 16). "The Gendered Fight Behind Sicily's Most Iconic Snack." BBC Travel. https://www.bbc.com/travel/article/20190415-the-gender-fight-behind-sicilys-most-iconic-snack.

Driel, E. and Verkuyten, M. (2020). "Local identity and the reception of refugees: the Example of Riace." Identities 27(5): 614-632.

Frazzetta, F. and Piazza, G. (2020). "The Protests of Migrants in Sicily: Why are there Few and Only SingleIssue?"Geopolitics. https://www.tandfonline.com/doi/ref/10.1080/14650045.2020.1716737?scroll=top.

Gattinara, P.C. (2017). "The 'Refugee Crisis' in Italy as a Crisis of Legitimacy." Contemporary Italian Politics. 9(3): 318-331.

Giglioli, I. (2017). "Producing Sicily as Europe. Migration, Colonialism and the Making of the Mediterranean Border between Sicily and Tunisia." Geopolitics. 22(2): 407-428.

Giglioli, I. (2017). "From 'A Frontier Land' to 'A Piece of North Africa in Italy': The Changing Politics of 'Tunisianness' in Mazara del Vallo, Sicily." International Journal of Urban and Regional Research 41: 749-766.

Hiers, W., Soehl T., and Wimmer, A. (2017). "National Trauma and the Fear of Foreigners: How Past Geopolitical Threat Heightens Anti-Immigration Sentiment Today.” Social Forces 96.1: 361-388.

Kristiansen, T.M. et al (2015). "The Significance of Everyday Life: An Ethnographic Study of Participation in Group-Based Patient Education." Advances in Applied Sociology 5: 81-93.

Zdzislaw, M. (1993). Symbols, Conflict, and Identity: Essays in Political Anthropology. Albany: SUNY Press.

Makarychev, A. (2018). "Bordering and Identity-Making in Europe After the 2015 Refugee Crisis." Geopolitics 23(4):747-753.

Mintz, S. and DuBois, M. (2002). "The Anthropology of Food and Eating." Annual Review of Anthropology 31(1): 99-119.

Montanari, M. (2012). Let the Meatballs Rest: And Other Stories About Food and Culture. New York: Columbia University Press.

Pollan, M. (2009). Food Rules: An Eater's Manual. New York: Penguin.

Rannard, G. (2018, August 24). "Diciotti: Rice Ball Protest in Italian Boat Row." BBC News. https://www.bbc.com/news/blogs-trending-

45296739\#: :text=Deep $\% 2$ Dfried $\% 20$ rice $\% 20$ balls $\% 20$ stuffed,the $\% 20$ port $\% 20$ of $\% 20$ Catania $\% 2 C \%$ 20Sicily.

Ratti, A.M. (1931). "Italian Migration Movements, 1876 to 1926." In Willcox, W.F (ed.). International Migrations, Volume II: Interpretations. New York: National Bureau of Economic Research.

Reddy, G. and van Dam, R. (2020). "Food, Culture, and Identity in Multicultural Societies: Insights from Singapore." Appetite 149.

Ruggeri, F. (2018). Sicilian Visitors: Volume Two - Culture. Lulu. 401-3.

https://books.google.com/books?id=2sZqDwAAQBAJ\&printsec=frontcover\&source=gbs_ge_summary $\_\mathrm{r} \& \mathrm{cad}=0 \#_{\mathrm{v}}=$ onepage $\& \mathrm{q} \& \mathrm{f}=$ false

Ruta, G. (2018, Aug 22). "Diciotti, la Protesta degli Arancini per i Migranti Bloccati al Porto di Catania.” La Repubblica https://video.repubblica.it/politica/diciotti-la-protesta-degli-arancini-per-i-migranti-bloccatial-porto-di-catania/312885/313515

Schwarz, C. (2018). "Eating Morality: Food and the Goodness of Care in Northern Aboriginal Australia." The Asia Pacific Journal of Anthropology 19(1): 19-34.

Schack, L. and Witcher, A. (2020). "Hostile hospitality and the Criminalization of Civil Society Actors Aiding Border Crossers in Greece." Environment and Planning: Society and Space 53.

Scherer, R. (1993). Zeus hospitalier: Eloge de l'hospitalite. Paris: Le Table Ronde. 
Varrella, S. (ed). (2020). "Number of Immigrants who Arrived by Sea in Italy from 2014 to 2020." Statista Research Department. https://www.statista.com/statistics/623514/migrant-arrivals-to-italy.

Tierney, K. and Ohnuki-Tierney, E. (2012). “Anthropology of Food.” In Pilcher, J.M. The Oxford Handbook of Food History. Oxford: Oxford University Press.

Urso, O. (2018). "The Politicization of Immigration in Italy: Who Frames the Issue, When and How." Italian Political Science Review/Rivista Italiana Di Scienza Politica, 48(3):365-381.

Wolf, E. (1982). Europe and the People Without History. Berkeley: University of California Press.

Wright, C. (2003). The Little Foods of the Mediterranean: 500 Fabulous Recipes for Antipasti... And More. Boston: The Harvard Common Press.

Yitmen, S. and Verkuyten, M. (2017). "Feelings Toward Refugees and non-Muslims in Turkey: The Roles of National and Religious Identifications, and Multiculturalism." Journal of Applied Social Pscyhology 48(2): 90100.

Zerback, T., et al. (2020). "Was Lampedusa a key Event for Immigration News? An Analysis of the Effects of the Lampedusa Disaster on Immigration Coverage in Germany, Belgium, and Italy." Journalism Studies. 21(6):748-765. 